\title{
Characteristics of undiagnosed COPD in a senior community center
}

\author{
This article was published in the following Dove Press journal: \\ International Journal of COPD \\ 15 October 2014 \\ Number of times this article has been viewed
}

\author{
Simeão Rodrigo Santos' \\ Elisângela Silva Lizzi ${ }^{2}$ \\ Elcio Oliveira Vianna ${ }^{3}$ \\ 'Postgraduate Community Health \\ Program, School of Medicine of \\ Ribeirão Preto, University of São \\ Paulo, ${ }^{2}$ Postgraduate Community \\ Health Program, School of Medicine \\ of Ribeirão Preto, University of \\ São Paulo, ${ }^{3}$ Associate Professor, \\ Respiratory Division, School of \\ Medicine of Ribeirão Preto, University \\ of São Paulo, São Paulo, Brazil
}

Objective: To determine the characteristics of undiagnosed chronic obstructive pulmonary disease (COPD) in a senior community center.

Methods: We performed a cross-sectional, observational study with the following procedures: questionnaire to record demographic and health status data, anthropometry, questionnaire about COPD risk factors and symptoms, spirometry, and socioeconomic evaluation. Simple logistic regression and multiple analyses were carried out to assess associations. The studied variables were tested for associations with previous COPD diagnosis.

Results: Three hundred and thirty-five subjects aged 50 years or older were recruited and 318 completed the protocol. Seventy-one (22\%) had presumptive COPD. Among them, 57 (80\%) did not have a previous physician-made diagnosis of COPD. We found no associations between previous diagnosis and socioeconomic status, anthropometric data, or risk factors. Regarding respiratory symptoms, there was an association between previous COPD diagnosis and wheezing $(P=0.011) . \mathrm{FEV}_{1}$ and $\mathrm{FVC}$ values were lower in the previous diagnosis group compared to the group without a previous diagnosis $(P<0.001$, Student's $t$-test). We found an association of lower $\mathrm{FEV}_{1}(<50 \%$ predicted value) with a previous diagnosis $(P=0.028)$.

Conclusion: Our results showed a high prevalence of undiagnosed obstructive ventilatory defects in a senior community center. Previous COPD diagnosis was associated with more severe disease and more frequent wheezing. This study highlights the potential of these centers to increase COPD diagnosis and to reduce its risks.

Keywords: diagnosis, spirometry, senior centers, prevalence, smoking, exercise

\section{Introduction}

Chronic obstructive pulmonary disease (COPD) is a chronic degenerative disease representing a significant component of the morbidity-mortality of a population. It has been estimated that COPD will be the third main cause of death in the world in 2030, with a $30 \%$ increase in deaths being projected for in the next 10 years unless measures are taken to reduce risk factors, increase case detection, and refine treatment. ${ }^{1}$

Although COPD is a highly prevalent disease, it is underestimated and underdiagnosed the world over. ${ }^{2}$ Individuals with COPD who were not diagnosed by a doctor are considered to be undiagnosed. The diagnosis of COPD should be considered for any individual with cough, expectoration, wheezing, dyspnea, and/or a history of exposure to risk factors, and should be confirmed by spirometry. ${ }^{3}$

The use of spirometry is essential for an early and rigorous diagnosis of COPD, reducing underdiagnosis, and permitting affected people to learn about the disease and its risk factors and symptoms. ${ }^{3}$
Correspondence: Elcio Oliveira Viann Seção de Pneumologia, Hospital das Clínicas de Ribeirão Preto.

Av. Bandeirantes, Ribeirão Preto,

São Paulo, Brazil

Tel +551636022706

Fax +551636020229

Email evianna@fmrp.usp.br
International Journal of COPD 20|4:9 ||55-||6|

Dovepress

http://dx.doi.org/10.2147/COPD.S4952 (c) (i) (9) 2014 Santos et al. This work is published by Dove Medical Press Limited, and licensed under Creative Commons Attribution - Non Commercial (unported, v3.0) License. The full terms of the License are available at http://creativecommons.org/licenses/by-nc/3.0/. Non-commercial uses of the work are permitted without any further permission how to request permission may be found at: http://www.dovepress.com/permissions.php 
The objective of the present study was to determine the frequency of, and the factors associated with undiagnosed COPD in a senior community center (SCC).

\section{Methods}

\section{Subjects and protocol}

An observational, analytical, cross-sectional study was conducted at a SCC that provides care for 600 users aged at least 50 years. The SCC is located in the city of Uberaba, Minas Gerais, Brazil, with an estimated population of 300,000 inhabitants. The study was approved by the Research Ethics Committee and all subjects gave written informed consent to participate. This committee fully obeys the norms of the International Conference on Harmonization Good Clinical Practice Guidelines, as well as Resolution number 196/96 of CNS/MS-Brazil.

The study was conducted on a convenience sample of 335 SCC users. Six hundred subjects used to attend the community center; the first 335 people of a list of users were enrolled. Data were collected from February 2012 to October 2012 on the premises of the SSC by a single investigator. After the subjects gave written informed consent, the following questionnaires and procedures were applied in the order indicated: screening card for demographic and health status data, anthropometric evaluation, questionnaire about risk factors and symptoms of COPD, spirometry, and a questionnaire for socioeconomic data.

For questions about symptoms and risk factors (tobacco and wood stove exposure), we have used questions from the European Community Respiratory Health Survey (ECRHS) questionnaire, translated into Portuguese, adapted to the Brazilian lexicon, and validated. ${ }^{4}$ We also asked: "Have you ever been told by a doctor that you have COPD, emphysema, or chronic bronchitis?".

We used the questions in the ECRHS questionnaire to explore smoking behavior. We asked whether the participants smoked at least one cigarette per day over the period of 1 year. If yes, we asked how many cigarettes he or she smoked per day and for how long. We also asked if the subject ceased to smoke and the date when the subject ceased. To be classified as a smoker, he or she needed to answer that they had smoked for at least 10 years. We considered subjects who had quit smoking at least 1 year earlier to be ex-smokers.

The Brazilian Economic Classification Criteria were used to determine the economic status of participants. This questionnaire was applied and yielded a score that determined the economic status of each individual according to the following categories (from higher to lower income): $\mathrm{A}_{1}, \mathrm{~A}_{2}, \mathrm{~B}_{1}, \mathrm{~B}_{2}, \mathrm{C}, \mathrm{D}$, and E. ${ }^{5}$

The inclusion criteria were: being a user of the SCC and being at least 50 years old. Noninclusion criteria were: having no cognitive ability to agree with, or to participate in the study. After the evaluation of eligibility, a sample of 335 users was obtained. The criteria for the diagnosis of presumptive COPD were: spirometry compatible with COPD, ie, the ratio of 1-second forced expiratory volume to forced vital capacity $\left(\mathrm{FEV}_{1} / \mathrm{FVC}\right)$ below lower limit of normal; having been exposed to tobacco smoking and/or firewood burning, and denying to have asthma when specifically asked about this diagnosis. Patients were considered to have a previous diagnosis of COPD when they had criteria for presumptive COPD and when they responded that they had a medical diagnosis of COPD, emphysema, or chronic bronchitis.

\section{Spirometry}

Spirometry was applied at the SCC, always by the same investigator using a pneumotachograph coupled to a computer equipped with a specific program for the analysis of pulmonary function (v4.14.9; Koko - PFT System Windows). Maneuvers and efforts followed the American Thoracic Society and European Respiratory Society recommendations. ${ }^{6}$ $\mathrm{FVC}, \mathrm{FEV}_{1}$, and their ratio $\left(\mathrm{FEV}_{1} / \mathrm{FVC}\right)$ were determined. The participants performed the tests in a seated position, using disposable mouthpieces and nose clips. Predicted values were calculated from reference equations for the Brazilian population. ${ }^{7}$ Reversibility test was not performed and patients' habitual medication were not discontinued for spirometry.

\section{Statistical analysis}

Statistical analysis was performed using the Data Analysis and Statistical Software (STATA; v10.0; StataCorp LP, College Station, TX, USA) based on a databank elaborated with the Excel program (v14.0; Microsoft Corporation, Redmond, WA, USA). The data were typed by two persons with a double entry for later verification of the existence of duplicate records and for the detection of inconsistencies between the two databases. The consistency of the fields was then determined and typing errors were corrected. Inconsistent data were checked in the records of the original interview.

Simple and multiple logistic regression were used for the dependent and independent categorical variables, association was determined by the odds ratio (OR) and its $95 \%$ confidence intervals, and the values are reported as the number of events and proportion. Data are reported as 
mean \pm standard deviation and the unpaired two-tailed Student's $t$-test was used for comparison of the continuous variables between groups. The level of significance was set at 0.05 in all analyses.

\section{Results}

Seventy-one individuals with presumptive COPD were detected in this sample. They were divided into two groups, ie, a group with no previous medical diagnosis of COPD $(80 \%, n=57)$ and a group with a previous diagnosis of the disease $(20 \%, n=14)$. The group without a previous diagnosis of COPD consisted of $63 \%$ males $(n=36)$ and $37 \%(n=21)$ females; the groups with a previous diagnosis consisted of $43 \%$ males $(n=6)$ and $57 \%$ females $(n=8)(P=0.119)$.

Analysis of the socioeconomic and anthropometric variables and of the risk factors for COPD showed no difference between presumptive COPD patients with no previous diagnosis and COPD patients with a previous diagnosis. In the group with no previous diagnosis, mean $( \pm \mathrm{SD})$ age was $72 \pm 8.1$ years and body mass index (BMI) was $27.2 \pm 4.6 \mathrm{~kg} / \mathrm{m}^{2}$. There was a predominance of males $(63 \%)$, completed elementary schooling (86\%), economic classification below $\mathrm{B}_{2}(74 \%)$, and living with accompanying persons (65\%). Regarding the risk factors studied, there was a $65 \%$ prevalence of smoking habit and a $96 \%$ prevalence of exposure to firewood burning. In the group with a previous diagnosis of COPD, the mean age was $69 \pm 8.5$ years, BMI was $25.7 \pm 5.0 \mathrm{~kg} / \mathrm{m}^{2}$, and there was a predominance of females (57\%), completed elementary schooling (71\%), economic classification below $\mathrm{B}_{2}(64 \%)$, and living with accompanying persons (57\%). There was a $79 \%$ prevalence of smoking habit and a $100 \%$ prevalence of exposure to firewood burning. Analysis of the continuous variables age and BMI did not reveal significant differences $(P>0.05)$ and analysis of the categorical variables did not show association $(P>0.05)$ between the independent ones (sex, age, schooling, economic classification, residence, smoker/ex-smoker) and the dependent variable (previous diagnosis of COPD; Table 1).

Regarding the respiratory symptoms, the group with a previous diagnosis of COPD showed greater occurrence of cough with expectoration and wheezing but did not differ from the other group regarding dyspnea. Simple logistic

Table I Characteristics of subjects with and without a previous diagnosis of COPD

\begin{tabular}{|c|c|c|c|c|}
\hline Variable - n (\%) & $\begin{array}{l}\text { Without a previous } \\
\text { diagnosis }\end{array}$ & $\begin{array}{l}\text { With a previous } \\
\text { diagnosis }\end{array}$ & OR $(95 \% \mathrm{CI})$ & $P$-value \\
\hline \multicolumn{5}{|l|}{ Presumptive COPD patients } \\
\hline Total & $57(80 \%)$ & I 4 (20\%) & & \\
\hline \multicolumn{5}{|l|}{ Sex } \\
\hline Female & $21(37 \%)$ & $8(57 \%)$ & Ref & \\
\hline Male & $36(63 \%)$ & $6(43 \%)$ & $0.437(0.133-1.434)$ & $0.172^{\mathrm{a}}$ \\
\hline Age - years ${ }^{c}$ & $72 ; S D=8.09$ & $69 ; \mathrm{SD}=8.52$ & & $0.348^{\mathrm{b}}$ \\
\hline \multicolumn{5}{|l|}{ Age range } \\
\hline $50-64$ years & $12(2 \mid \%)$ & $4(29 \%)$ & I.333 (0.244-7.279) & $0.740^{\mathrm{a}}$ \\
\hline $65-79$ years & $33(58 \%)$ & $7(50 \%)$ & Ref & \\
\hline$\geq 80$ years & $12(21 \%)$ & $3(21 \%)$ & $0.750(0.137-4.094)$ & $0.740^{\mathrm{a}}$ \\
\hline BMI $\left(\mathrm{kg} / \mathrm{m}^{2}\right)^{\mathrm{c}}$ & $27.22 ; S D=4.65$ & $25.68 ; S D=5.02$ & & $0.280^{\mathrm{b}}$ \\
\hline \multicolumn{5}{|l|}{ Schooling } \\
\hline Complete elementary school & 49 (86\%) & 10 (71\%) & Ref & \\
\hline Beyond elementary school & $8(14 \%)$ & $4(29 \%)$ & $2.450(0.616-9.733)$ & $0.203^{\mathrm{a}}$ \\
\hline \multicolumn{5}{|l|}{ Economic classification } \\
\hline Below $B_{2}$ & $42(74 \%)$ & $9(64 \%)$ & Ref & \\
\hline$\geq \mathrm{B}_{2}$ & $15(26 \%)$ & $5(36 \%)$ & I.555 (0.449-5.386) & $0.484^{\mathrm{a}}$ \\
\hline \multicolumn{5}{|l|}{ Residence } \\
\hline Without an accompanying person & $20(35 \%)$ & $6(43 \%)$ & Ref & \\
\hline With an accompanying person & $37(65 \%)$ & $8(57 \%)$ & $0.720(0.219-2.369)$ & $0.590^{\mathrm{a}}$ \\
\hline \multicolumn{5}{|l|}{ Smoker/ex-smoker } \\
\hline No & $20(35 \%)$ & $3(2 \mid \%)$ & Ref & \\
\hline Yes & $37(65 \%)$ & II (79\%) & I.98I (0.494-7.938) & $0.181^{\mathrm{a}}$ \\
\hline \multicolumn{5}{|l|}{ Exposure to firewood burning } \\
\hline No & $2(4 \%)$ & $0(0)$ & & \\
\hline Yes & $55(96 \%)$ & $14(100 \%)$ & $*$ & $*$ \\
\hline
\end{tabular}

Notes: aMultiple Logistic Regression; 'Student's t-test; 'data are reported as mean \pm SD; *insufficient information (cell $=0$ ). The Brazilian Economic Classification Criteria yields scores that determine the economic status of each individual (from higher to lower income): $A_{1}, A_{2}, B_{1}, B_{2}, C, D$, and $E$.

Abbreviations: BMI, Body Mass Index; Cl, confidence interval; COPD, chronic obstructive pulmonary disease; OR, odds ratio; Ref, reference category; SD, standard deviation. 
regression analysis revealed an association $(P=0.011)$ with the wheezing symptom (Table 2).

Milder reductions in $\mathrm{FEV}_{1}$ were more frequent than $\mathrm{FEV}_{1}<50 \%$ in the group with no previous diagnosis of COPD, while moderate $\mathrm{FEV}_{1}$ reduction $(50 \% \leq$ $\mathrm{FEV}_{1}<80 \%$ ) predominated in patients with a previous diagnosis. Simple logistic regression analysis revealed an association $(P=0.031)$ between $\mathrm{FEV}_{1}<50 \%$ and the report of a previous diagnosis. The spirometric variables showed lower values in the group with a previous diagnosis. The unpaired two-tailed Student's $t$-test revealed a significant difference $(P<0.01)$ in $\mathrm{FEV}_{1}$ and the $\mathrm{FEV}_{1} / \mathrm{FVC}$ ratio between groups (Table 3).

\section{Discussion}

The present study showed a prevalence of presumptive COPD of approximately $25 \%$ among individuals aged 50 years or older frequenting a SCC. Of these patients, $80 \%$ reported that they had no previous medical diagnosis of the disease. Comparison of patients with a previous diagnosis of COPD to patients without a previous diagnosis revealed an association between a previous diagnosis and greater disease severity detected on the basis of worse spirometry results $\left(\mathrm{FEV}_{1}\right.$ and $\left.\mathrm{FEV}_{1} / \mathrm{FVC}\right)$. In addition, there was an association between a previous diagnosis and a history of wheezing.

The lack of a diagnosis, and consequently of treatment of COPD may play an important role in the increased morbidity and mortality due to this disease. A correct diagnosis during

Table 2 Symptoms of subjects with and without a previous diagnosis of COPD

\begin{tabular}{|c|c|c|c|c|}
\hline $\begin{array}{l}\text { Variable - } \\
\text { n (\%) }\end{array}$ & $\begin{array}{l}\text { Without a } \\
\text { previous } \\
\text { diagnosis }\end{array}$ & $\begin{array}{l}\text { With a } \\
\text { previous } \\
\text { diagnosis }\end{array}$ & OR $(95 \% \mathrm{Cl})^{\mathrm{a}}$ & $P$-value \\
\hline \multicolumn{5}{|c|}{ Presumptive COPD patients } \\
\hline \multicolumn{5}{|c|}{ Cough with expectoration ${ }^{\mathrm{b}}$} \\
\hline No & $27(47 \%)$ & $6(43 \%)$ & Ref & \\
\hline Yes & $30(53 \%)$ & $8(57 \%)$ & $1.2(0.3-3.9)$ & 0.716 \\
\hline \multicolumn{5}{|l|}{ Wheezing ${ }^{\mathrm{b}}$} \\
\hline No & $35(61 \%)$ & $3(2 \mid \%)$ & Ref & \\
\hline Yes & $22(39 \%)$ & II (79\%) & $5.8(1.4-23.2)$ & 0.012 \\
\hline \multicolumn{5}{|l|}{ Dyspnea $^{\mathrm{b}}$} \\
\hline No & $36(63 \%)$ & $7(50 \%)$ & Ref & \\
\hline Yes & $21(37 \%)$ & $7(50 \%)$ & $1.7(0.5-5.5)$ & 0.345 \\
\hline \multicolumn{5}{|c|}{ Any of the symptoms ${ }^{b}$} \\
\hline No & $16(28 \%)$ & $0(0)$ & & \\
\hline Yes & $41(72 \%)$ & $14(100 \%)$ & $*$ & $*$ \\
\hline
\end{tabular}

Notes: aSimple logistic regression; *insufficient information (cell $=0$ ). b $V$ alues are reported as $\mathrm{n}(\%)$.

Abbreviations: $\mathrm{Cl}$, confidence interval; $\mathrm{COPD}$, chronic obstructive pulmonary disease; OR, odds ratio; Ref, reference category; SD, standard deviation.
Table 3 Comparison of spirometry values between subjects with and without a previous diagnosis of COPD

\begin{tabular}{|c|c|c|c|c|}
\hline Variable - n (\%) & $\begin{array}{l}\text { Without } \\
\text { a previous } \\
\text { diagnosis }\end{array}$ & $\begin{array}{l}\text { With } \\
\text { a previous } \\
\text { diagnosis }\end{array}$ & $\begin{array}{l}\text { OR } \\
(95 \% \mathrm{CI})\end{array}$ & $P$-value \\
\hline \multicolumn{5}{|c|}{ Presumptive COPD patients } \\
\hline \multicolumn{5}{|c|}{ FEV, category } \\
\hline $\begin{array}{l}\geq 80 \% \text { of } \\
\text { predicted } F E V_{1}\end{array}$ & 27 (47\%) & $3(21 \%)$ & $\begin{array}{l}0.460 \\
(0.11-1.96)\end{array}$ & $0.274^{c}$ \\
\hline $50 \% \leq \mathrm{FEV},<80 \%$ & $28(49 \%)$ & 7 (50\%) & Ref & \\
\hline $\mathrm{FEV}_{1}<50 \%$ & $2(4 \%)$ & $4(29 \%)$ & $\begin{array}{l}8.00 \\
(1.21-88.85)\end{array}$ & $0.03 I^{c}$ \\
\hline $\mathrm{FEV}_{1} \%{ }^{\mathrm{b}}$ & $\begin{array}{l}78.80 \\
S D=16.85\end{array}$ & $\begin{array}{l}62.64 \\
S D=22.91\end{array}$ & & $<0.0 \mathrm{I}^{\mathrm{d}}$ \\
\hline $\mathrm{FVC} \%{ }^{\mathrm{b}}$ & $\begin{array}{l}94.3 \mathrm{I} \\
S D=17.50\end{array}$ & $\begin{array}{l}89.78 \\
S D=19.76\end{array}$ & & $0.400^{d}$ \\
\hline $\mathrm{FEV}_{1} / \mathrm{FVC}^{\mathrm{b}}$ & $\begin{array}{l}0.64 \\
S D=0.05\end{array}$ & $\begin{array}{l}0.54 \\
S D=0.15\end{array}$ & & $<0.0 \mathrm{I}^{\mathrm{d}}$ \\
\hline
\end{tabular}

Notes: ${ }^{a}$ Values are reported as $\mathrm{n}(\%)$; ${ }^{b}$ values are reported as mean $\pm \mathrm{SD}$; ' simple logistic regression; ‘Student's $t$-test.

Abbreviations: $\mathrm{OR}$, odds ratio; $\mathrm{Cl}$, confidence interval; $\mathrm{COPD}$, chronic obstructive pulmonary disease; $\mathrm{FEV}_{1}$, I-second forced expiratory volume; FVC, forced vital capacity; Ref, reference category; SD, standard deviation.

the early phase of the disease would permit intervention in the risk factors, especially smoking, thus preventing additional deterioration of airway obstruction and would also have positive results in economic terms regarding disease management. ${ }^{8}$ A late diagnosis made when the patients have reached a more severe pattern of airflow obstruction, with more marked and frequently exacerbated respiratory symptoms results in more onerous treatments for the health system and greater repercussions on the health status and functional capacity of affected individuals. ${ }^{9}$

In view of the high prevalence of COPD, of the costs and suffering imposed by the disease on affected individuals and on society, it is necessary to reduce the proportion of undiagnosed cases, a task that needs to be accomplished by the health system. On the other hand, screening for COPD by spirometry is not recommended for asymptomatic individuals. These directives are based on the fact that hundreds of asymptomatic cases must be evaluated in order to avoid only a single exacerbation. ${ }^{10-12}$ Even so, the above authors and others ${ }^{13-15}$ recommend spirometry screening of specific groups, including groups of symptomatic individuals. In the present study, $77 \%$ of the cases were symptomatic. Thus, this sample is a specific group to be addressed for detection of COPD cases and for individual evaluation before physical activity in the SCC. In a recent review article, Csikesz and Gartman argued in favor of early COPD diagnosis. In the future, strategies for early detection will be associated with more therapeutic options to improve long-term survival. ${ }^{16}$ 
In the present study, the degree of obstruction and the symptoms were greater in COPD patients with a previous diagnosis, a fact suggesting that the disease was diagnosed in its more advanced phase. The most severe degrees of obstruction were significantly more prevalent in the group with a previous medical diagnosis. These results indicate that more frequent diagnosis in more severe cases is probably due to more intense symptoms that generate the need for care or that are more easily noted by the patient's relatives. Other studies carried out in other countries with objectives similar to ours also showed that more severe COPD patients are more likely to receive a diagnosis than patients with milder COPD. ${ }^{2,9}$

The presence of wheezing was also associated with a greater proportion of a previous diagnosis. A possible explanation of this fact could be that wheezing is a more objective symptom than dyspnea or cough and that it can be perceived by third parties. It is not an expected symptom, whereas cough is considered to be habitual, chronically accepted, and typical of persons who smoke. Thus, the onset of wheezing more frequently induces the patients to seek medical care.

Taken together, our results permit us to infer that patients with more severe COPD as determined by both spirometry and symptoms are those who seek medical care and therefore are more aware of their disease. Patients with less severe disease tend to receive no medical diagnosis even when they frequent a unit belonging to the public health system. The implementation of spirometry in this scenario has the potential of reversing this situation of absence of diagnosis.

A recent study conducted in five countries in Latin America (Proyecto Latinoamericano de Investigación en Obstrucción Pulmonar) (The PLATINO Project) showed that $89 \%$ of the participants had not been previously diagnosed as COPD patients. ${ }^{17} \mathrm{~A}$ similar study in US showed that $75 \%$ of the participants had not been previously diagnosed. ${ }^{9}$ This study was conducted in a developed country, indicating that the socioeconomic question is not the only determinant of lack of diagnosis. The socioeconomic evaluation performed by us was based on schooling level, which was low for both presumptive COPD patients without a previous diagnosis and for patients with a diagnosis of COPD, supporting the concept that there is no association between lack of diagnosis and socioeconomic level.

Our expectation for a population using a SCC with a majority of members who practice physical activity was that the prevalence of COPD would be low and that the prevalence of smoking would also be reduced since these are people who looked for prevention and for health care. However, there was a high prevalence of COPD, smoking, and lack of COPD diagnosis, a fact indicating the valuable potential of these centers for the detection of COPD and the risks involved in the condition. Thus, the present study is peculiar and original regarding this characteristic.

The age variable has been considered to be a risk factor for COPD. ${ }^{1}$ Some studies have shown an increased prevalence of COPD in parallel with increasing age. ${ }^{18,19}$ When we grouped COPD patients according to the presence of a previous medical diagnosis, we noted that there was no significant difference in age. When we stratified the patients by age, the prevalence of undiagnosed COPD also did not differ between age ranges.

Studies published in different parts of the world have shown a higher prevalence of undiagnosed COPD among women, as well as a tendency to diagnose men more frequently on the part of the medical community. ${ }^{20,21}$ The present study did not confirm this theory since there was no significant association between sex and diagnosis.

Smoking is the main risk factor for COPD. A Danish study that followed up 8,045 individuals over a period of 25 years estimated that $25 \%$ of smokers developed COPD during this period. ${ }^{22}$ The present study showed a $68 \%$ prevalence of exposure to smoking among COPD patients, with $65 \%$ being undiagnosed and $79 \%$ diagnosed, with no association with this factor. Another risk factor studied was exposure to firewood burning. Uberaba, Minas Gerais, is a developing city that has attracted persons who were born and lived in the rural zone during adolescence and even during part of adult life, and thus had been exposed to or using wood-burning stoves in poorly ventilated spaces. Exposure to firewood burning was found in $96 \%$ of presumptive COPD patients and in 100\% of diagnosed patients. Exposure to firewood burning was more prevalent than smoking among women and men, an important result regarding collective actions for the prevention of the disease. ${ }^{23}$

Among the limitations of the present study is the fact that the diagnosis of COPD can vary according to the criteria adopted. By using spirometry and questionnaires, we may obtain different results compared to those obtained with medical visits and other exams such as measurement of lung diffusion, imaging exams, and measurements of pulmonary inflammation. Although some guidelines have proposed a COPD definition independent of post-bronchodilator spirometry, ${ }^{24,25}$ most recent guidelines have defended the use of post-bronchodilator $\mathrm{FEV}_{1} .{ }^{1}$ Other limitations we should mention are the lack of a more precise asthma diagnosis, lack of reversibility test, possible interference of habitual medication on spirometry data, asthma-COPD overlap, and the fact that this SCC is not strictly for senior people. 
In conclusion, the present results show a high prevalence of undiagnosed presumptive COPD and of a previous diagnosis associated with greater disease severity. The use of spirometry in SCC may be a simple and useful strategy for increasing the number of COPD diagnoses. As a result, effective measures could be implanted for the treatment and control of the disease, reducing the impact of advanced COPD and improving the quality of life of the patients and their relatives.

\section{Acknowledgments}

We wish to thank the City of Uberaba and the staff of the senior community center, as well as Miss Elizabet Sobrani for help with the preparation of field work.

\section{Financial support}

Coordenação de Aperfeiçoamento de Pessoal de Nível Superior (Coordination for the Improvement of Higher Education Personnel), Fundação de Amparo à Pesquisa do Estado de São Paulo (São Paulo Research Foundation), Fundação de Apoio ao Ensino e Pesquisa de Ribeirão Preto (Ribeirão Preto Research and Medical Teaching Foundation), (Núcleo de Apoio à Pesquisa em Doenças Inflamatórias [Group for Research in Inflammatory Diseases] [NAPDIN] under grant agreement no 11.1.21625.01.0).

\section{Disclosure}

The authors report no conflicts of interest in this work.

\section{References}

1. Global Initiative for Chronic Obstructive Lung Disease - GOLD [homepage on the Internet]. Global Strategy for the Diagnosis, Management, and Prevention of COPD - Revised 2011 [cited February 20,2013]. Bethesda, MD: Global Initiative for Chronic Obstructive Lung Disease. Available from: http://www.goldcopd.org/uploads/ users/files/GOLD_Report_2011_Feb21.pdf. Accessed August 29, 2014.

2. Lindberg A, Bjerg A, Rönmark E, Larsson LG, Lundbäck B. Prevalence and underdiagnosis of COPD by disease severity and the attributable fraction of smoking Report from the Obstructive Lung Disease in Northern Sweden Studies. Respir Med. 2006;100(2):264-272.

3. Pauwels RBA, Calverley P, Jenkins CSH. Global strategy for the diagnosis, management and prevention of chronic obstructive pulmonary disease. NHLBI/WHO Global Initiative for Chronic Obstructive Lung Disease (GOLD) Workshop summary. Am J Respir Crit Care Med. 2001;163(5):1256-1276.

4. European Community Respiratory Health Survey. Variations in the prevalence of respiratory symptoms, self-reported asthma attacks, and use of asthma education in the European Community Respiratory Health Survey (ECRHS). Eur Respir J. 1996;9(4):687-695.

5. Associação Brasileira das Empresas de Pesquisa (ABEP). Brazil Economic Classification Criterion, 2010. São Paulo, Brazil: Associação Brasileira das Empresas de Pesquisa. Available from: http://www.abep. org/new/criterioBrasil.aspx. Accessed February 21, 2014.
6. Miller MR, Hankinson J, Brusasco V, et al; ATS/ERS Task Force. Standardization of spirometry. Eur Respir J. 2005;26(2):319-338.

7. Pereira CA, Barreto SP, Yesões JG, Pereira FW, Gerstler JG, Nakatani J. Reference values for spirometry in a sample of the adult Brazilian population. J Pneumol. 1992;18:10-22.

8. Miravitlles M. Economic evaluation of the impact of chronic obstructive pulmonary disease and its acute exacerbations on Latin America. J Bras Pneumol. 2004;30(3):274-285.

9. Coultas DB, Mapel D, Gagnon R, Lydick E. The health impact of undiagnosed airflow obstruction in a national sample of United States adults. Am J Respir Crit Care Med. 2001;164(3):372-377.

10. Qaseem A, Snow V, Shekelle P, et al; Clinical Efficacy Assessment Subcommittee of the American College of Physicians. Diagnosis and management of stable chronic obstructive pulmonary disease: a clinical practice guideline from the American College of Physicians. Ann Intern Med. 2007;147(9):633-638.

11. US Preventive Services Task Force. Screening for chronic obstructive pulmonary disease using spirometry: US Preventive Services Task Force. Ann Intern Med. 2008;148(7):529-534.

12. Qaseem A, Wilt TJ, Weinberger SE, et al; American College of Physicians; American College of Chest Physicians; American Thoracic Society; European Respiratory Society. Diagnosis and management of stable chronic obstructive pulmonary disease: a clinical practice guideline update from the American College of Physicians, American College of Chest Physicians, American Thoracic Society, and European Respiratory Society. Ann Intern Med. 2011;155(3):179-191.

13. Riegels-Jakobsen T, Skouboe M, Dollerup J, et al. Municipality screening of citizens with suspicion of chronic obstructive pulmonary disease. Int J Chron Obstruct Pulmon Dis. 2012;7:35-41.

14. Schirnhofer L, Lamprecht B, Firlei N, et al. Using targeted spirometry to reduce non-diagnosed chronic obstructive pulmonary disease. Respiration. 2011;81(6):476-482.

15. Ulrik CS, Løkke A, Dahl R, et al. Early detection of COPD in general practice. Int J Chron Obstruct Pulmon Dis. 2011;6:123-127.

16. Csikesz NG, Gartman EJ. New developments in the assessment of COPD: early diagnosis is key. Int J Chron Obstruct Pulmon Dis. 2014;9:277-286.

17. Menezes AM, Perez-Padilla R, Jardim JR, et al; PLATINO Team. Chronic obstructive pulmonary disease in five Latin American cities (the PLATINO study): a prevalence study. Lancet. 2005;366(9500): 1875-1881.

18. Lindberg A, Jonsson AC, Rönmark E, Lundgren R, Larsson LG, Lundbäck B. Prevalence of chronic obstructive pulmonary disease according to BTS, ERS, GOLD and ATS criteria in relation to doctor's diagnosis, symptoms, age, gender, and smoking habits. Respiration. 2005;72(5):471-479.

19. Yamasaki A, Hashimoto K, Hasegawa Y, et al. COPD is frequent in conditions of comorbidity in patients treated with various diseases in a university hospital. Int J Chron Obstruct Pulmon Dis. 2010;5:351-355.

20. de Torres Tajes JP, Macario CC. Infradiagnóstico de la enfermedad pulmonar obstructiva crónica en mujeres: cuantificación del problema, determinantes y propuestas de acción [Chronic obstructive pulmonary disease in women]. Arch Bronconeumol. 2010;46 Suppl 3:23-27. Spanish.

21. Soares S, Costa I, Neves AL, Couto L. Characterisation of a population at increased risk of COPD. Rev Port Pneumol. 2010;16(2):237-252.

22. Løkke A, Lange P, Scharling H, Fabricius P, Vestbo J. Developing COPD: a 25 year follow up study of the general population. Thorax. 2006;61(11):935-939.

23. Jain NK, Thakkar MS, Jain N, Rohan KA, Sharma M. Chronic obstructive pulmonary disease: does gender really matter? Lung India. 2011;28(4):258-262.

24. National Collaborating Centre for Chronic Conditions. Diagnosing COPD. Thorax. 2004;59(Suppl 1):i27-i38.

25. Halpin D. NICE guidance for COPD. Thorax. 2004;59(3):181-182. 
International Journal of COPD

\section{Publish your work in this journal}

The International Journal of COPD is an international, peer-reviewed journal of therapeutics and pharmacology focusing on concise rapid reporting of clinical studies and reviews in COPD. Special focus is given to the pathophysiological processes underlying the disease, intervention programs, patient focused education, and self management protocols.

This journal is indexed on PubMed Central, MedLine and CAS. The manuscript management system is completely online and includes a very quick and fair peer-review system, which is all easy to use. Visit $\mathrm{http}: / /$ www.dovepress.com/testimonials.php to read real quotes from published authors.

Submit your manuscript here: http://www.dovepress.com/international-journal-of-copd-journal 